Learning about one way of learning

Rudi Lutz

Machine Learning: An Artificial Intelligence Approach, Vol. II. Edited by Ryszard S. Michalski, Jaime G. Carbonell and Tom M. Mitchell. Morgan Kaufmann: 1986. Pp.738. Distributed by W.H. Freeman, \$39.95, £35.95.

MACHINE learning, a subfield of artificial intelligence (AI) has been studied for the past two or three decades with the dual intentions of furthering our understanding of the learning process in human beings, and enabling machines to learn from experience or improve their performance at some task by being explicitly taught. Within this time AI has had many impressive achievements, both practical and theoretical. But (with the possible exception of some expert systems) AI in general has not yet achieved its aims of mimicking human performance at very many tasks, and many workers feel that advances in machine learning will prove to be the key to the whole endeavour.

Historically, there have been two main paradigms in machine learning. One of these is the study of networks of simple neuron-like processing elements, which learn by modifying the strengths of the interconnections between the elements in the network. Before about 1970, the most important of such networks was the class known as perceptrons, but most work on neural networks was abandoned (until recently) after Minsky and Papert's discovery in 1969 of several fundamental theoretical limitations on the kinds of task perceptrons could perform. The other paradigm has been that of symbol manipulation, in which the concepts being learned are expressed in symbolic terms (typically represented by data structures in the computer memory) and in which the learning prograr.. may already have been given domain-dependent knowledge.

Machine Learning Vol. II is a sequel to a book published in 1983 (reviewed in $\mathrm{Na}$ ture 308, 89; 1984) and, like its predecessor, it is concerned wholly with the second of the two paradigms. As such it succeeds admirably, giving a clear impression of current knowledge of this type of learning. The various chapters are actually the extended and rewritten papers of the Second International Workshop on Machine Learning, held in 1983, but the contributors have been very successful in their aim of presenting their results in a "tutorial fashion"; because of this, the book will not only be useful to research workers but also to students and others wishing to acquaint themselves with the field. It collects together in one volume many results and

important theoretical insights not easily available elsewhere.

Amongst the high points are Paul Utgoff's contribution on how a system can change its own criteria for forming generalizations as it learns; a paper by Robert Berwick on a general learning principle he calls the "Subset Principle", which can enable a learning system to learn a concept from only positive instances of the concept; and Silver's discussion of a technique he calls Precondition Analysis, which enables a program to learn problem-solving strategies from worked examples. Many other interesting results are presented by other authors, but it is not always clear what general conclusions can be drawn from them.

\section{Flowering of art}

\section{Anthony Huxley}

Orchids from Curtis's Botanical Magazine. Edited by Samuel Sprunger. Cambridge University Press:1986. Pp. 525. $£ 85, \$ 150$

ANYONE remotely interested in orchids will find this large volume irresistible. In a $9^{\prime \prime} \times 12^{\prime \prime}$ format it presents 1,176 facsimile portraits of orchids, being all those published in Curtis's Botanical Magazine between its launch in 1787 and the abandonment of hand-coloured plates in 1948 . Some are reproduced at full page size, most at four to a page.

The aim of the "Bot.Mag.", as its founder William Curtis set it out, was to illustrate and describe "the most ornamental Foreign Plants, cultivated in the Open Ground, the Green House and Stove" ("Stove" meaning a hothouse). About one in five of all the plants illustrated were orchids, and this volume encompasses about one species in twenty of all known species worldwide, including most of those seen in cultivation. Here are the progenitors of the myriads of hybrid orchids which fanciers mostly grow today, though one might dare to ask why anyone should bother with man-made hybrids when their parents are mostly so beautiful, remarkable or both.

The editor, a Swiss orchid specialist, has provided "catalogues" at the end of the book which cite each orchid's present correct name and its synonyms, with an indication of which name was used in Curtis. The main catalogue contains the orchids in the present volume; a shorter one covers those appearing from 1948 to 1983 , when methods of colour reproduction other than hand colouring (by then becoming impossibly expensive) were used. It seems a pity, perhaps, that these 98 plates could not have been included, even though some of the pleiones have been
The main fault of the book is that it does not address the other, "neuronal" (connectionist) learning paradigm, which has had a major revival recently. This is partly because many of the exciting new developments in this approach, bringing together results from computer science, neurobiology and artificial intelligence, have only arisen since the Workshop in 1983. For a book that is almost certain to become a major reference work this is something of a drawback, but on the whole Michalski and his colleagues have put together a useful contribution to the machine learning field.

Rudi Lutz is in the Cognitive Studies Programme, University of Sussex, Brighton BN1 $9 Q N$, UK

illustrated before. Both catalogues give countries of origin and a code refers to the plants' mode of life (epiphytic, terrestrial, and so on). There is also a full index including all the synonyms.

The Introduction, by Dr Phillip Cribb, curator of the Orchid Herbarium at Kew, describes the history of the illustrations and illuminates the lives of Curtis and the thirty or so artists who have produced the plates over the years. A few made great numbers - one of the earliest, Sydenham Edwards, nearly 1,650, and Walter Fitch around 2,800. As Dr Cribb notes, some 550 of Fitch's orchids were depicted "at a time when new species were flooding in from all parts of the world...", many being thus seen by the public for the first time, and many indeed being new to science. William Jackson Hooker, who became Director of Kew, himself illustrated 64 orchids among a large number of other plants, and also wrote the accompanying text.

This text, which in the Botanical Magazine faces every plate, is not reproduced in the present publication, if only because it would have made it impossibly unwieldy. In perfectionist terms this is a pity, although some of the original accounts are inadequate or even misleading; but one cannot have everything. What one does have is an unparalleled pictorial reference to the variability of this remarkable family of plants that overlies the botanical format that makes each of them an orchid: an amazing bit of evolution.

Anthony Huxley, 50 Villiers Avenue, Surbiton, Surrey KT5 $8 B D$, UK, is a writer and photographer specializing in botanical and horticultural subjects. Among other books he is co-author of Wild Orchids of Britain and Europe (Chatto \& Windus, 1983).

- Recently available in Britain is the second edition of Plant Systematics, by Samuel B. Jones Jr and Arlene E. Luchsinger. The book is primarily an undergraduate text, but will also be useful to amateur and professional botanists. Publisher is McGraw-Hill, price is hbk £34.95, pbk (due in March) $£ 10.95$. 